\title{
Estética cotidiana y literatura: posibilidades de una confluencia para un problema de investigación
}

\section{Everyday Aesthetics and Literature: Possibilities of a Confluence for an Investigative Problem}

\author{
Horacio Pérez-Henao \\ Universidad de Medellín \\ hperez@udem.edu.co
}

\section{Resumen:}

El artículo sugiere un punto de encuentro entre la teoría de la estética cotidiana y el estudio literario. Ello con el fin de formular los primeros lineamientos de un problema de investigación con el que se busca configurar una estética cotidiana a partir del estudio de la literatura.

Palabras clave: estética, estética cotidiana, arte y vida, literatura y vida.

\section{Abstract:}

This paper suggests a meeting ground for everyday aesthetics theory and literary study. The main purpose is to formulate the first outlines of a research problem which seeks to configure an everyday aesthetics based on the study of literature.

Keywords: Everyday Aesthetics, Aesthetics, Art and Life, Literature and Life. 


\section{El arte objeto: ¿fetiche en las teorías estéticas?}

En la tradición académica occidental, las aproximaciones a la estética como objeto de estudio han estado vinculadas al arte. En los terrenos propios de la obra artística, filósofos, historiadores, sociólogos, teóricos del lenguaje y estetólogos en general, han descifrado reiteradamente las condiciones esenciales de la estética, a saber: la belleza y su conexión con el arte. El interés, además, por categorías como juicio, gusto, forma, contenido y experiencia estética, entre otras, ha propiciado la construcción de un corpus teórico que genera confusión al momento de concretar una respuesta a las preguntas ¿qué es arte?, o, ¿por qué el arte? (Plebe).

En la mayoría de los casos, las disquisiciones han dado lugar a disímiles miradas que insisten en el entorno y contorno del objeto-arte. Las perspectivas menos objetuales, que intentan focalizar sus análisis por fuera de los límites del objeto en un interés por dar cuenta del sujeto receptor, del ingenio creador o de los contextos psicológicos y sociohistóricos en relación con el arte, paradójicamente han acentuado la mirada sobre el objeto-arte. Es decir, aunque intentan formular una diferenciación entre arte y estética, no logran desprenderse de las estéticas tradicionales que volcaron todos sus esfuerzos teóricos al señalar, casi por antonomasia, lo estético como el objeto arte.

Las estéticas filosófica, psicológica, idealista, lingüística, semántica, fenomenológica, científica, marxista y existencialista, entre otras, han intentado esclarecer desde posturas radicales los terrenos propios de lo estético y lo artístico. En el extremo de mostrar lo estético como objeto, la estética experimental -por ejemplo- llegó a sugerir que la forma del objeto y su finalidad bastaban para herir y estimular nuestro sentido estético (Fechner, cit. en Sprung y Sprung). De manera que la forma sería suficiente en el mundo del arte, y el artista bien podría refugiarse en su torre de marfil sin preocuparse del contenido de aquella. Los sonidos, los ritmos, las imágenes, los colores, las líneas, las masas y los movimientos, en sus relaciones objetivas, constituirían el único material del cual se serviría el verdadero artista: esos, no otros, serían sus medios de expresión (García 50). Al tenor de estas afirmaciones, las teorías estéticas iban en busca de fórmulas capaces de dar cuenta de la estética, tal como lo criticó Dessoir al referirse a la estética de la empatía: "Las fórmulas explica-todo amenazan con sobrevalorar la concreción de los problemas en la ilusión de que el único y verdadero cometido de la estética sería el de encontrar la fórmula" (cit. en Plebe 24).

Digamos, entonces, que estas teorías han recorrido un camino arduo -no exento de críticas- en sus búsquedas por irradiar cientificidad a sus postulados. Herederas del positivismo, el rigorismo y la filosofía analítica, que predominaron en gran parte del siglo XX, erigieron visiones de carácter metafísico, en las cuales el objeto-arte se localizaba -cual dato observable- en el laboratorio de las teorías y en ausencia perenne del acontecer cotidiano del sujeto, o en aproximaciones supuestamente alejadas de la mirada cientificista y con la pretensión de un "genérico llamamiento a la actividad del sujeto en el ámbito estético" (Plebe 34), acogieron una estética idealista (Croce) cuya tesis esencial fue el arte-intuición 
o arte-expresión. Pero Croce, según Volkelt (cit. en Plebe), no solo relegaba la distinción entre intuición artística e intuición no artística al reino de lo cuantitativo (ciencia), dando una respuesta apresurada a la cuestión diferenciadora, sino que insinuaba un valor estético para todo tipo de intuición y consagraba a la empiria la tarea de distinguir el arte de lo que no es arte (Plebe 35). Refiriéndose a Croce, Plebe se pregunta si sería necesaria una estética filosófica, ¿por qué no dejar entonces todos esos estudios al dominio de la experimentación? (36). Es decir, la fijación cientificista en el objeto-arte persistía, no obstante la pretensión croceana de hablar del sujeto activo en lo estético.

Tributarios de estas perspectivas son los estudios en los que durante mucho tiempo imperó el análisis formal y estructural de la literatura. Se concebía la primacía significativa del texto como un objeto que se bastaba a sí mismo en cuanto a sus posibilidades estéticas. De alguna manera, la obra literaria, siguiendo el camino de los formalistas rusos (Todorov, Teoría de la literatura de los formalistas rusos), era autorreferencial, dado que entre sus propias paredes se hallaba la explicación intrínseca a su condición estética. Aproximación similar hizo el estructuralismo (Barthes, Propp) al explicar el funcionamiento interno del relato, buscando, además, la construcción de una estructura universal como modelo aplicable a cualquier relato (Castro, Posada). En el mismo sentido, la nueva crítica (Ransom) exigía un estudio sistemático del texto como objeto autorreferencial de significado, mientras que la llamada semiótica de París y el grupo Tel Quel "consideraban la obra como solo Ecriture, suprimiendo al lector y olvidándose de que la literatura es comunicación" (Jauss 21). Según estas teorías estéticas, el individuo y el entorno sociohistórico quedan por fuera de cualquier posibilidad de contribuir a la comprensión, interpretación y análisis del arte. ¿Es posible comprender el arte como un objeto aislado del mundo de la vida?

Los planteamientos de Dewey, al contrario, dan un giro a la teoría del arte, en tanto combaten el error de las perspectivas tradicionales que "consideran el arte por fuera del ambiente histórico, natural y social en el que está inmerso y del que no es separable" (Plebe 87). En efecto, para Dewey:

[...] cuando las obras de arte son separadas de las condiciones en que nacen y de las condiciones en que operan en la experiencia, se forma en torno suyo un muro que hace casi opaco su significado general, que es el que constituye el objeto de una teoría estética (7).

El autor propone, entonces, una mirada que amplía el fenómeno artístico en tanto resultado de los modos de relación que los sujetos del arte configuran mediante la organización de la experiencia. Se trata de comprender la continuidad entre el arte y la vida, de tal forma que lo estético no sería asunto exclusivo de museos, galerías o conciertos de ópera, sino que su acontecer tomaría forma en la posibilidad experiencial del individuo. Es decir, lo estético en el arte es ante todo experiencia subjetiva. Al respecto, Dewey toma distancia de teorías que asumen la experiencia estética a partir de las peculiaridades del objeto-arte (experiencia objetivista). Desde la perspectiva deweyana hay un énfasis en la experiencia estética como categoría central en la concepción del arte; y "aunque parezca 
ser la quintaesencia de la estética", señala Mandoki que "la idea de la experiencia estética es bastante reciente, pues no aparece en la teoría sino hasta el siglo XIX, basada en ideas de fines del siglo XVII y XVIII" (46). La autora, citando a Townsend, indica el desarrollo del concepto de experiencia estética desde Shaftesbury, Hutcheson, Baumgarten y Kant, que culmina con el intento de Dewey por "describir y cualificar a la experiencia estética a partir de la introspección del sujeto en su aspecto cualitativamente distinto de las experiencias cotidianas" (Mandoki 46-7).

Justamente, en El arte como experiencia, Dewey diferencia (lo que él denomina) la mera experiencia de la experiencia estética. Aunque, en efecto, en su obra el mundo de la vida y el individuo cobran interés al momento de abordar la obra de arte, y por consiguiente su cualidad estética, precisa con rigor la imposibilidad de asumir el flujo de la vida diaria como experiencia: "Las cosas son experimentadas, pero no de manera que articulen una experiencia [estética]" (Dewey 41); ello, en tanto que en la dimensión de la cotidianidad nos caracterizamos por ser distraídos, dispersos, incoherentes y por interrumpir nuestros quehaceres (experiencias) sin que necesariamente los hayamos terminado. Contrario a estas meras experiencias, la experiencia estética corresponde a una articulación demarcada por un comienzo que sigue su curso hasta su consumación final, dando el carácter de unidad a lo experimentado. En este sentido, la experiencia estética se ancla en un desarrollo básicamente controlado por un orden que el artista (productor) establece a fin de que su obra sea gozada tanto en la percepción propia como en la del espectador. Así lo precisa Dewey:

El acto de producir dirigido por el intento de producir algo que se goza en la experiencia inmediata de la percepción, posee cualidades que no tiene la actividad espontánea y sin control. El artista, mientras trabaja, encarna en sí mismo la actitud del que percibe (56).

En este orden de ideas, podríamos decir que la lectura completa de una novela, la visualización de una película o la asistencia a un concierto de música clásica, serían paradigmas de la experiencia estética en términos de Dewey. En los tres ejemplos anotados es fácil deducir que la configuración de cada una de esas obras de arte (en su creación y recepción) es el resultado de un proceso estructural en el cual las partes constituyen una unidad y, además, siempre se encaminan hacia un final (clausura). De ahí su carácter de experiencia estética: unidad y clausura. Complementariamente, Dewey introduce otros conceptos que diferenciarían la experiencia estética de la mera experiencia. Se trata de la relación íntima que establece entre el hacer y el padecer. Así lo ejemplifica:

Un hombre hace algo, levanta, digamos, una piedra; en consecuencia, padece, sufre algo: peso, dureza, textura de la superficie de la cosa levantada. Las propiedades así padecidas determinan un acto ulterior. La piedra o es muy pesada, o muy angular o no es suficientemente sólida; o bien las propiedades padecidas muestran que es adecuada

1 Destacado en el original. 
para el uso al que se destina. El proceso continúa hasta que surge una mutua adaptación del yo y el objeto, y esta experiencia particular llega a una conclusión. Lo que es cierto en este ejemplo simple vale, en cuanto a la forma, para toda experiencia. La criatura que opera puede ser un pensador en su estudio y el ambiente con el cual está en interacción puede consistir en ideas en vez de piedras. Sin embargo, la interacción de los dos constituye la experiencia total obtenida, y la terminación que la completa es la constitución de una armonía sentida (51).

Y más adelante asegura:

Una experiencia tiene modelo y estructura, porque no es solamente un hacer y un padecer que se alterna, sino que consiste en éstos y sus relaciones. La acción y las consecuencias deben estar juntas en la percepción. Esta relación es la que da significado; captarla es el objetivo de toda inteligencia (51).

Luego afirma que "la experiencia está limitada por todas las causas que interfieren con la percepción de las relaciones entre padecer y hacer” (Dewey 52).

Así las cosas, la experiencia estética no se consuma si en el sujeto experiencial no se alojan decisivamente un estado de conciencia, la percepción de la relación entre hacer y padecer, y el reconocimiento cognoscitivo de los vínculos armoniosos entre los distintos elementos que conforman la unidad estructural encaminada hacia una finalización. Esto indica, por ejemplo, que nunca podría darse una experiencia estética en los terrenos del inconsciente. Es más, aquel que lance una piedra distraídamente estará por fuera de los presupuestos teóricos de Dewey. Porque si bien el autor defiende que la posibilidad de la experiencia estética surge de mecanismos básicos que aplicamos en nuestra vida diaria, en su teoría logra intuirse unos parámetros restrictivos a tal posibilidad. Esta teoría parece incluso restringir la misma obra de arte, en tanto que se la concibe, en lo fundamental, como una estructura que comporta cierta complejidad en las relaciones de sus componentes que le permite asegurarse unidad y clausura. Sin embargo, la dinámica artística, máxime en nuestros días, da señales de obras de arte caracterizadas preferiblemente por la fragmentación, no por la unidad ni la clausura (obras abiertas).

En el ámbito de la vida diaria, por otro lado, Dewey estrecha el camino que conduce a lo estético de lo cotidiano, pues por obvias razones, su preocupación mayor sigue estando alrededor de la obra de arte. Desde su aproximación teórica, lo estético cotidiano es mirado a través del filtro de la experiencia artística. En otras palabras, la mera experiencia no llegaría a ser experiencia estética en tanto que no es estructurada, no tiene unidad, ni complejidad ni clausura. ¿Podríamos decir que el gozo de un individuo que, distraídamente, pasa la tarde del domingo sentado en un parque viendo pasar gente, corresponde a una experiencia estética? Posiblemente los conceptos de unidad y clausura resultan débiles al momento de una teoría estética, tal como lo insinúa Irvin ("The Pervasiveness of the Aesthetic in Ordinary Experience"), o como lo advierte Mandoki: "No es pertinente preguntarse qué hace que una experiencia sea estética y otra no lo sea, sino 
cuáles son las condiciones de la posibilidad de la estesis" (50). Porque, desde el punto de vista de esta última autora, "toda experiencia es por definición estética, pues experienciar equivale a estesis. Pero no toda experiencia es artística ya que esta ocurre solo en relación con obras de arte" (50). ¿Es posible, entonces, una experiencia estética de la vida cotidiana sin los condicionamientos del hacer, padecer unidad y clausura?

\section{Estética cotidiana: ¿Cómo ampliar la dimensión estética a las distintas esferas de la vida?}

La pregunta por lo cotidiano desde una perspectiva estética no es nueva. Hacia finales del siglo XX y comienzos del XXI se ha registrado un interés creciente por desmarcar la teoría estética de su dominante y exclusiva relación con la obra de arte y, sobre todo del arte occidental, con el fin de vincularla como cualidad frecuente de la vida diaria. Esta aproximación ha dado paso a lo que hoy se conoce como estética cotidiana, una subdisciplina desde la cual los teóricos "claim that the activities not essentially conncected to art or nature can have aesthetic properties and/or that they can give rise to significant aesthetic experiences" (Irvin, "Aesthetics of the Everyday" 137). Es decir, se reconoce que el transcurrir de la vida diaria posee un penetrante cariz estético que incluye actividades relacionadas con la comida, los olores, los sabores, el medio ambiente, el deporte, el sexo, lo extraño, lo familiar, el clima o los lugares significativos, por mencionar algunos tópicos recurrentes.

Si bien Dewey amplió el ámbito de discusión en la teoría estética, es claro que las aproximaciones de la estética cotidiana se distancian de sus planteamientos pues - paradójicamente- restringió la experiencia estética de la vida diaria al concebirla como el resultado de una actividad estructurada sobre la base de las categorías de hacer, padecer, unidad y clausura. En su contra, Irvin ("Scratching an Itch") se pregunta si tales categorías son realizables en un acto tan simple como rascarse una picazón o, mejor, inquiere, si ese mismo acto entrañaría componentes estéticos por sí mismo. El cuestionamiento de Irvin ("Scratching an Itch") conduce, no obstante, a precisar las propiedades de la estética en la vida diaria. En tal sentido, Leddy sugiere las categorías de orden, limpieza, bueno, nuevo, bello y divertido como las cualidades estéticas más relevantes en actividades de la vida diaria, tales como ir de compras, viajar en transporte urbano, habitar la casa o el lugar de trabajo, e ir a sitios de diversión. Se evidencia con ello un impulso por relocalizar (dar un nuevo locus) la discusión teórica sobre la estética para ubicarla en el escenario de la cotidianidad. La visión de Leddy, sin embargo, no deja de ser tributaria de aquella percepción kantiana de asignar propiedades básicamente agradables y bellas a lo estético. Pues con base en las categorías sugeridas, todo parece indicar que el tejido de la vida diaria solo está constituido de circunstancias agradables y bellas. Siendo así, asegura Mandoki, la estética quedaría reducida a una disciplina totalmente trivial (54). La autora cuestiona las perspectivas que dan la espalda al lado horroroso, violento, trágico 
o sucio de lo cotidiano, y advierte que "este miedo a las impurezas de lo cotidiano tendrá que ser superado si pretendemos encontrar en la estética algo más que su reducción a una inofensiva teoría de lo bello y el arte" (53).

La perspectiva de Mandoki aboga, pues, por una mirada amplia en torno a la estética cotidiana (prosaica), en tanto que su categoría central de análisis es la estesis, que en cierto modo logra desprenderse de las categorías que, aun en la subdisciplina aquí mencionada, arrastran con un pasado difícil de dejar. El fantasma del pasado teórico aparece cada vez que la estética se explica a través de la obra de arte, lo bello y categorías como armonía, contemplación, distanciamiento, actitud estética o experiencia estética. Al recurrir a la estesis, Mandoki intenta abarcar la totalidad de la existencia humana desde una posición fundamentalmente estética. No se trataría solamente de ciertas actividades, situaciones o fenómenos de la vida diaria dignos de una cualidad estética particular, sino que sería la estética una dimensión fundamental de la existencia humana. Por ello, en Mandoki la estética es el estudio de la condición de estesis; al precisar su categoría central de análisis, afirma:

\begin{abstract}
Entiendo por estesis a la sensibilidad o condición de abertura, permeabilidad o porosidad del sujeto al contexto en que está inmerso. Por lo tanto, si lo enfocamos a la escala humana, ya no plantearemos como problema fundamental del campo de estudio de la estética a la "experiencia estética" (que literalmente significaría la bella experiencia, o la redundancia de la experiencia experiencial, o bien la experiencia que resulta del estudio del arte y lo bello), sino a la condición de estesis como abertura del sujeto en tanto expuesto a la vida. En suma, lo que nos interesa explorar en este trabajo no son ya esos momentos privilegiados que se han dado en denominar "contemplación estética" sino a esa condición del ser vivo que consiste en estar abierto al mundo. No hay estesis sin vida, ni vida sin estesis. Se trata, pues, de la condición fundamental de todo ser viviente (67).
\end{abstract}

En cualquier caso, las diversas perspectivas dentro de la misma subdisciplina de la estética cotidiana reconocen que en el transcurrir de la vida diaria existe -como decíamos antes- un penetrante cariz estético que incluye actividades relacionadas con la comida (Saito, "Everyday aesthetics"), los olores y los sabores (Brady), lo extraño y lo familiar (Haapala), el clima (Saito, “The aesthetics of weather"), el paisaje (Carlson), el deporte (Welsh), las picazones (Irvin, "Scratching an Itch") y el medio ambiente (Saito, "Future Directions for Enviromental Aesthetics"), entre otras.

Desde este abordaje, el arte (y en consecuencia la literatura) se desplaza a un plano secundario, pues el enfoque de la estética cotidiana lo que intenta es precisamente desmarcarse de la antonomasia estética-arte vehiculada por las teorías tradicionales, que han erigido al arte en el referente absoluto de lo estético. ¿Cómo propiciar una confluencia entre estética cotidiana y arte? 


\section{Estética cotidiana y arte: ¿Es posible la vida cotidiana como obra de arte?}

La respuesta a la pregunta anterior puede rastrearse a través de algunas teorías estéticas y prácticas artísticas que tienden a estrechar la relación arte y vida diaria o arte y estética cotidiana. En este intento, el dadaísmo (Ball, Tzara), como vanguardia, resquebraja toda concepción del arte e incluso aparece como un movimiento negacionista que pone en duda la existencia del arte, la literatura y la poesía. Claro está, los dadaístas no eliminan el arte, lo que pretenden es llevarlo a la vida diaria y someterlo a su azaroso transcurrir: "el arte ya no es un estímulo emocional serio e importante, ni una tragedia sentimental, sino el resultado de la experiencia vivida y de la alegría de vivir" (Richter 54). Por su parte, el situacionismo (Vaneigem), como movimiento artístico y político, persigue unir la vida al arte en una totalidad creativa, de tal manera que la praxis estética sea revolucionaria (Vidal) y propicie la emancipación del individuo en sociedad (Debord). Mientras tanto, el arte relacional concentra su práctica artística en las relaciones humanas y su contexto social (Bourriaud), encaminada a una experiencia de encuentro más que a la producción de obras acabadas (Costa). La pretensión de unos y otros es dar al arte un locus por fuera del museo, la galería o el teatro, y materializarlo en los escenarios de la vida diaria.

De manera similar, otros acercamientos señalan cómo las obras de arte y los objetos diseñados estéticamente mejoran la vida diaria, en una suerte de continuidad entre arte y cotidianidad y, a su vez, redefinen la práctica artística como un hacer experto y dedicado de artefactos que sirven en diversas funciones para la vida diaria (Sartwell 9). Desvincular, por otro lado, el arte popular de la vida cotidiana resultaría improbable, toda vez que este (televisión, música, por ejemplo) toma lo mundano como fuente primordial de creación y se integra a la vida diaria en su consumo (Novitz). En el campo de los estudios literarios, ciertos enfoques explicitan su interés de conectar el mundo de la vida al análisis del texto. Las aproximaciones marxistas (Lukács) y las postestructuralistas (Derrida, Deleuze y Kristeva) asientan sus perspectivas en una visión historicista, a la par de teorías como el feminismo (Bowen, Gilbert y Felski) y el poscolonialismo (Said y Mignolo), desde las cuales el texto literario es estudiado con base en diversos referentes sustancialmente políticos de la vida social.

Desde otro ángulo, el texto literario representa una opción para estar abiertos al intercambio de ideas y la revisión de los valores en nuestros contextos sociales (Booth). Esta aproximación se inscribe dentro del llamado pluralismo (Booth), que pretende recobrar la literatura como una instrucción valiosa y valorable, e inscribirla dentro de una teoría y crítica éticas. Esta apertura se conecta, a su vez, con los estudios culturales (Hoggart, Hall y Williams), en el propósito de identificar las fuerzas que construyen la vida diaria y las formas de generación de sentidos. En similares direcciones, la literatura, y particularmente la ficción, es proyectada al mundo de la vida diaria cuando se intenta buscar la comprensión de la realidad o su función en la cotidianidad. Para Bruner, la ficción da forma al mundo 
real, idea que resuena en la afirmación de Eco cuando asegura que los grandes libros han contribuido a modelar el mundo. Calvino, en su doble función de teórico y escritor, expresa su malestar por la pérdida de forma que constata en la vida, y a la cual -como defensaopone una idea de literatura (69). En otros escenarios, el estudio literario se propone en tanto posibilidad de contribuir a la formación de los servidores públicos. En esa línea, Nussbaum se pregunta qué sentido de la vida encarna la imaginación literaria (28). Por último, Todorov (La literatura en peligro) concibe el texto literario como un espacio mediante el cual se accede a una mejor comprensión del mundo y de la condición humana. El texto, por consiguiente, ha sido construido por otros que han tenido una comprensión superior de la vida y el individuo. Así, el estudio de la literatura no tiene como fin saber más de literatura, exhibir la experticia en el arte literario al estilo de profesores, críticos y escritores que aseguran que "la literatura solo habla de sí misma" (Todorov, La literatura en peligro 84 ). Se trata de una dimensión estética más amplia, en la que las palabras de los poetas y los novelistas permiten dar forma a los sentimientos que experimentamos, ordenar el curso de los pequeños acontecimientos que constituyen la vida y ayudan a conocer lo real y actuar sobre él (Todorov, La literatura en peligro 67).

Estas perspectivas de estudio literario, sin embargo, no hacen referencia a la denominada estética cotidiana. No existe un vínculo evidente entre texto y estética cotidiana, a fin de hacerlos coincidir en una teoría (o teorías) sobre la cual el texto literario dé elementos de comprensión de la estética cotidiana. La relación intenta producirse entre literatura y algunos asuntos del mundo de la vida (dar forma a la realidad, reconsideración de los valores, instrucción para la vida pública, la comprensión de la vida, etcétera). La ausencia de tal conexión podría explicarse al revisar lo expuesto en estas páginas. Por un lado, observamos las visiones proclives a una mayor abstracción en la teoría del arte, con pretensiones trascendentales que, obviamente, anulan la inmanencia de la obra artística a la vida diaria. De otra parte, vemos los impulsos de ciertas vanguardias apresuradas en romper con los cánones del arte establecidos, y que conciben la dimensión estética de la cotidianidad en tanto esta adopte o se le invista del carácter arte, en un esfuerzo por, en términos de Danto, propiciar la transfiguración del lugar común. Pero la cotidianidad no se impregna de su dimensión estética solo en la medida en que es transformada en obra de arte. Bien es cierto que en la demarcación de los límites de la estética de la vida diaria las referencias categoriales -la mayoría de las veces- están en relación con las teorías estéticas sobre el arte (armonía, equilibrio, placer, etcétera); ello, sin embargo, no conduce obligatoriamente a transformar en arte los olores, la comida, el clima, el medio ambiente o los objetos (escenarios en donde se instalan los estudios de estética cotidiana). Se trata, en lo fundamental, de reconocer las condiciones, cualidades o particularidades que caracterizarían la cotidianidad en su dimensión estética, es decir, una estética cotidiana; tarea, esta, adelantada en gran medida por los teóricos de la estética cotidiana.

Y en lo atinente al estudio literario, la conjunción entre texto y vida diaria aparece en algunos autores que intentan mostrar -mediante sus teorizaciones sobre la literatura- la 
estrecha relación entre uno y otro. No obstante, las elaboraciones a este respecto acogen asuntos gruesos del ámbito social, en tanto pertenecen a los temas de la ética (pluralismo), la política (marxismo, postestructuralismo), la realidad (Bruner, Eco y Calvino), la vida en general (Todorov) o la justicia (Nussbaum).

En tal sentido, al menos en las tendencias teóricas y los autores señalados aquí, lo banal (lo cotidiano) de la vida diaria no entra en el circuito de intereses del análisis, interpretación y estudio del texto literario. La vida cotidiana, tradicionalmente desdeñada por el pensamiento filosófico y de la que hay que desprenderse para elevar la meditación, es justamente la vida no filosófica (Lefebvre, cit. en Morales 519). No obstante, habría una manera no banal de ver la banalidad (Morales 519) que da lugar a teorías menos indiferentes a la vida diaria. Esto, por ejemplo, formula De Certeau al descubrir una creatividad cotidiana en tanto poiesis del quehacer ordinario.

Ahora bien, es necesario reconocer que la literatura nunca ha estado separada de la vida (Bloom 47). Empero, ciertos estudios literarios, en sus búsquedas trascendentalistas, se distancian de ella, entrampados en la paradoja desnudada por Husserl (cit. en Herrera) al aludir al yo que filosofa, al yo trascendental: "Todo Yo trascendental es un hombre en el mundo" (261). En palabras de Herrera, "el Yo trascendental, no es otro que el Yo de carne y hueso que transita por las calles" (261). En una suerte de paráfrasis, digamos que un estudio literario con pretensiones trascendentales no escapa a la penetrante inmanencia de la vida cotidiana virtualmente contenida en el texto. La vida cotidiana, entonces, constituiría el a priori de la creación y reflexión literarias. En la creación literaria el autor captura -mediante el lenguaje- las dimensiones de la vida que, a su vez, impregna de un modo estético. En la reflexión (estudio, interpretación, análisis), el lector reconocería ese modo estético de las dimensiones de la vida plasmadas por el lenguaje en el texto. De acontecer dicho reconocimiento, podríamos arriesgarnos a la posibilidad de configurar una teoría sobre la estética cotidiana a partir del estudio de la literatura. Tal estudio posibilitaría, así lo intuimos, una ampliación, intensificación y enriquecimiento de la vida del estudiante de literatura, que le permitiría hacer vínculos de sentido para crear formas de ser en el mundo.

\section{Referencias}

Ball, Hugo. Flight of time: a Dada diary. Nueva York, NY: Viking Press, 1974. Medio impreso. Barthes, Roland. "Introducción al análisis estructural del relato". En Roland Barthes, Umberto Eco y Tzvetan Todorov. Análisis estructural del relato. Buenos Aires: Tiempo contemporáneo, 1970. 39-64. Medio impreso.

Bloom, Harold. Anatomía de la influencia. La literatura como modo de vida. Madrid: Taurus, 2011. Medio impreso.

Booth, Wayne. The Company We Keep: An Ethics of Fiction. Berkeley: University of California Press, 1998. Medio impreso. 
Brady, Emily. "Sniffing and savoring: The aesthetics of smells and tastes". The aesthetics of everyday life. Eds. Andrew Light y Jonathan M. Smith. Nueva York: Columbia University Press, 2005. 177-93. Medio impreso.

Bruner, Jerome. Making stories: law, literature, life. Cambridge: Harvard University Press, 2003. Medio impreso.

Bourriaud, Nicolas. Estética relacional. Buenos Aires: Adriana Hidalgo, 2006. Medio impreso. Bowen, Barbara. Gender in the theater of war: Shakespeare's Troilus and Cressida. Nueva York: Garland, 1993. Medio impreso.

Calvino, Ítalo. Seis propuestas para el próximo milenio. Madrid: Siruela, 2001. Medio impreso. Carlson, Allen. "What's the correct curriculum for Landscape?". The aesthetics of everyday life. Eds. Andrew Light y Jonathan M. Smith. Nueva York: Columbia University Press, 2005. 92-108. Medio impreso.

Castro, Óscar y Consuelo Posada. Manual de teoría literaria. Medellín: Universidad de Antioquia, 1994. Medio impreso.

Costa, Flavia. "De qué hablamos cuando hablamos de 'arte relacional"'. Ramona 88 (2009). 9-17. Medio impreso.

Croce, Benedetto. The aesthetic as the science of expression and of the linguistic in general. Trad. Colin Lyas. Nueva York: Cambridge University Press, 1992. Medio impreso.

Danto, Arthur. La transfiguración del lugar común: una filosofía del arte. Barcelona: Paidós, 2002. Medio impreso.

De Certeau, Michel. La invención de lo cotidiano I: artes de hacer. México D.F.: Universidad Iberoamericana, 2007. Medio impreso.

Debord, Guy. La sociedad del espectáculo. Valencia: Pre-Textos, 2005. Medio impreso.

Deleuze, Gilles. La isla desierta y otros textos. Valencia: Pre-Textos, 2005. Medio impreso.

Derrida, Jacques. La escritura y la diferencia. Madrid: Anthropos, 1989. Medio impreso.

Dewey, John. El arte como experiencia. Barcelona: Paidós, 2008. Medio impreso.

Eco, Umberto. "La literatura, pasión que cambia la realidad". La Nación. 20 de septiembre de 2000. <http://www.lanacion.com.ar/215999-la-literatura-pasion-que-cambiala-realidad $>$. Fecha de ingreso: 11 de agosto de 2012. Sitio web.

Felski, Rita. Beyond feminist aesthetics: feminist literature and social change. Cambridge: Harvard University Press, 1989. Medio impreso.

García, Carlos. Teorías estéticas. Madrid: Eisa, 1962. Medio impreso.

Gilbert, Sandra y Susan Gubar. La loca del desván: la escritora y la imaginación literaria del siglo XIX. Madrid: Cátedra, 1998. Medio impreso.

Haapala, Arto. "On the aesthetics of everyday: familiarity, strangeness and the meaning of place". The aesthetics of everyday life. Eds. Andrew Light y Jonathan M. Smith. Nueva York: Columbia University Press, 2005. 39-55. Medio impreso.

Hall, Stuart. "Cultural studies: two paradigms". Media Culture and Society 2 (1980). 57-72. Medio impreso.

Herrera, Daniel. "Husserl y el mundo de la vida". Franciscanum 12(153) (2010). 247-74. Medio impreso. 
Hoggart, Richard. Contemporary cultural studies: an approach to the study of literature and society. Brimingham: University of Brimingham, 1969. Medio impreso.

Irvin, Sherri. "The Pervasiveness of the Aesthetic in Ordinary Experience". British Journal of Aesthetics 48 (2008). 29-44. Medio impreso.

---. "Scratching an Itch". The Journal of Aesthetics and Art Criticism 66(1) (2008). 25-35. Medio impreso.

---. "Aesthetics of the Everyday". A Companion to Aesthetics. 2a ed. Eds. Stephen Davies y Robert Hopkins. Chichester: Weley Blackwell, 2009. 136-9. Medio impreso.

Jauss, Hans. Experiencia estética y hermenéutica literaria: ensayos en el campo de la experiencia estética. Madrid: Taurus, 1992. Medio impreso.

Kristeva, Julia. El tiempo de la novela. Madrid: Lumen 1981. Medio impreso.

Leddy, Tom. "The nature of everyday aesthetics". The aesthetics of everyday life. Eds. Andrew Light y Jonathan M. Smith. Nueva York: Columbia University Press, 2005. 3-22. Medio impreso.

Mandoki, Katya. Estética cotidiana y juegos de la cultura. Prosaica I. México, D.F.: Siglo XXI, 2006. Medio impreso.

Mignolo, Walter. "La colonialidad a lo largo y a lo ancho: el hemisferio occidental en el horizonte colonial de la modernidad". Estudios transatlánticos postcoloniales I: narrativas comando/sistemas mundos: colonialidad/modernidad. Eds. Ileana Rodríguez y Josebe Martínez. Barcelona: Anthropos, 2010. Medio impreso.

Morales, Nelson. "Filosofía de lo cotidiano y ritmanálisis". Fermentum 11(32) (2001). 515-24. Medio impreso.

Novitz, David. The Boundaries of Art. Philadelphia: Temple University Press, 1992. Medio impreso.

Nussbaum, Martha. Justicia poética. Santiago de Chile: Andrés Bello, 1997. Medio impreso.

Plebe, Armando. Proceso a la estética. Trad. Vicente Jarque. Valencia: Guada, 1993. Medio impreso.

Propp, Vladimir. Morfología del cuento. Madrid: Fundamentos, 1985. Medio impreso.

Ransom, John. The New Criticism. Westport: Greenwood Press, 1941. Medio impreso.

Richter, Hans. Historia del dadaísmo. Buenos Aires: Nueva Visión, 1973. Medio impreso.

Said, Edward. Cultura e imperialismo. Barcelona: Anagrama, 2004. Medio impreso.

Saito, Yuriko. "Everyday aesthetics". Philosophy and Literature 25(1) (2001). 87-95. Medio impreso.

---. "The aesthetics of weather". The aesthetics of everyday life. Eds. Andrew Light y Jonathan M. Smith. Nueva York: Columbia University Press, 2005. 156-76. Medio impreso.

---. “Future Directions for Enviromental Aesthetics”. Enviromental Values 19 (2010). 37391. Medio impreso.

Sartwell, Crispin. The Art of Living: Aesthetics of the Ordinary in World Spiritual Traditions. Albany: State University of New York Press, 1995. Medio impreso.

Shusterman, Richard. Pragmatist Aesthetics: Living Beauty, Rethinking Art. Lanham: Rowman \& Littlefield, 2000. Medio impreso. 
Sprung, Lothar y Helga Sprung. "Gustav Theodor Fechner y el surgimiento de la psicología experimental”. Revista Latinoamericana de Psicología 15(3) (1983). 349-68. Medio impreso.

Todorov, Tzvetan. Teoría de la literatura de los formalistas rusos. Madrid: Siglo XXI, 1970. Medio impreso.

---. La literatura en peligro. Trad. Noemí Sobregués. Barcelona: Círculo de lectores, 2009. Medio impreso.

Townsend, Dabney. "From Shaftesbury to Kant: The Development of the Concept of Aesthetic Experience". Journal of the History of Ideas 48(2) (1987). 287-305. Medio impreso.

Tzara, Tristan. El hombre aproximativo. Madrid: Visor, 1975. Medio impreso.

Vaneigem, Raoul. The revolution of everyday life. Londres: Rising Free Collective, 1979. Medio impreso.

Vidal, Felipe. “Arte postmoderno y emancipación”. A Parte Rei 23 (2002). <http://serbal. pntic.mec.es/ cmunoz11/posmoderno.pdf $>$. Fecha de ingreso: 26 de abril de 2012. Sitio web.

Welsh, Wolfgang. "Sport viewed aesthetically, and even as art". The aesthetics of everyday life. Eds. Andrew Light y Jonathan M. Smith. Nueva York: Columbia University Press, 2005. 135-55. Medio impreso.

Williams, Raymond. Writing in society. Londres: Verso, 1983. Medio impreso. 